\title{
Spatial Variability Analysis of Soil Properties Using Geospatial Technique in Katni District of Madhya Pradesh, India
}

\author{
P. Dey ${ }^{1}$, S. Karwariya ${ }^{12^{*}}$ and N. S. Bhogal ${ }^{1}$ \\ ${ }^{1}$ Indian Institute of Soil Science, ICAR, Bhopal, MP-462038, India. \\ ${ }^{2}$ National Institute of Hydrology (NIH), Roorkee (UK), India.
}

\begin{abstract}
Authors' contributions
This work was carried out in collaboration between all authors. Authors PD and NSB designed the study. Author SK performed the statistical analysis, wrote the protocol and first draft of the manuscript.

Author SK also managed the analyses of the study and literature searches. All authors read and approved the final manuscript.

Article Information

DOI: $10.9734 /$ IJPSS/2017/34219

Editor(s):

(1) Marco Trevisan, Faculty of Agricultural Sciences, Institute of Agricultural and Environmental Chemistry, Catholic University of the Sacred Heart, Italy.

(2) L. S. Ayeni, Adeyemi College of Education, Ondo State, Nigeria. Reviewers:

(1) Augrey H. Malambo, University of Zambia, Zambia. (2) Funso Raphael Kutu, North-West University, South Africa.

(3) Isin Onur, Akdeniz University, Turkey. Complete Peer review History: http://www.sciencedomain.org/review-history/20006
\end{abstract}

Original Research Article

Received $18^{\text {th }}$ May 2017

Accepted $8^{\text {th }}$ July 2017

Published $12^{\text {th }}$ July 2017

\begin{abstract}
This study was conducted in Katni district of Madhya Pradesh India to map the spatial variability of major soil properties using geospatial technique. Surface soil samples of 505 locations $(0-15 \mathrm{~cm})$ were collected by random sampling strategy using GPS. Soil physico-chemical properties were measured in laboratory. In this paper we execute and compare the accuracy of various ordinary kriging methods. Spatial variability of soil physico-chemical properties was quantified through semivariogram analysis and the relevant surface maps were prepared through ordinary kriging. Exponential model fits well with experimental semi-variogram of $\mathrm{pH}, \mathrm{OC}$, available $\mathrm{N}, \mathrm{P}, \mathrm{K}, \mathrm{S}$ and $\mathrm{Zn}$, where as in case of electric conductivity best fitted model was spherical. Coefficient of variation of soil properties showed large variability with greatest variation observed in $\mathrm{Zn}(140 \%)$ while EC, $\mathrm{OC}, \mathrm{N}, \mathrm{P}$, and $\mathrm{K}$ has displayed moderate spatial variation whereas the smallest variation was in $\mathrm{pH}$ $(14.16 \%)$. In case of EC and $P$ the goodness of prediction $(G)$ had a negative value while $N, P, K$,
\end{abstract}


$\mathrm{pH}, \mathrm{Zn}$ and $\mathrm{S}$ shows positive value. The $\mathrm{pH}$ value in north-east part of the study area was alkaline and in the south-west portion of area was acidic in nature. Correlation coefficient between soil nutrients shows strong positive relationship between Nitrogen and organic carbon $(r=0.955)$. Cross validation of kriged map shows that spatial prediction of soil nutrients using semi-variogram parameters is better than assuming mean of observed value for any un-sampled location.

Keywords: Geostatistics; ordinary kriging; spatial interpolation; semi-variogram; correlation coefficient.

\section{INTRODUCTION}

Soil is the soul of life. An intimate knowledge on their spatial location, extent, distribution characteristics, classification, is a prerequisite for agricultural practices. Soil resource inventory provides an insight into the potentialities \& limitation of soil for its effective exploitation [1]. Soils are characterized by a high degree of spatial variability due to the combined effect of physical, chemical and biological processes that operate with different intensities and at different scales [2].

In recent years, considerable interest has been generated in assessment of the physical, chemical, and biological quality of agricultural soils [3,4]. Knowledge on spatial variation of soil properties is important in several disciplines, including Landuse planning, agricultural field trial research and precision farming. In precision farming, the concept of 'management zone' was evolved in response to this large variability with the main purpose of efficient utilization of agricultural inputs with respect to spatial variation of soils and its properties [5,6,7]. The most common way to gather knowledge in this aspect is to prepare soil surface maps through spatial interpolation technique by using point-based measurements of soil properties [8]. Geostatistical analyses were first developed in the 1950 's as a result of interest in areal or block averages for ore reserves in the mining industry geostatistics has been applied in soil science for more than 30 years $[9,10,11]$. It has been observed that among different methods of spatial interpolation of soil properties, kriging is an optimal interpolation method [12]. Kriging is an advanced geostatistical technique which produce predicted surface from scattered sample points by using $z$-values. It uses the semi-variogram to quantify the spatial variation of a regionalized variable. The fitted function to the experimental semi-variogram provides the input parameters for spatial prediction by kriging [13]. Geostatistical methods can provide reliable estimates for unsampled locations provided that the sampling interval resolves the variation at the level of interest [14]. Spatial prediction techniques, also known as spatial interpolation techniques, differ from classical modeling approaches in that they incorporate information on the geographic position of the sample data points [15]. The common interpolation techniques estimate the property of any unknown location by using weighted average of nearby or known data. A number of factors affect map quality including the nature of the soil variability [16], intensity of sampling and method of interpolation. Availability of various interpolation methods has raised a question to the researchers that which is the most appropriate method in different contexts is used for best accuracy. Among statistical methods, geo statistical kriging-based techniques [17] are widely applied, this model estimate values at un sampled locations based on the measurement at surrounding locations with certain assigned weights for each measurement. From a theoretical stand point, kriging is the optimal interpolation method [12], however, its correct application requires an accurate determination of the spatial structure via semi variogram construction and model-fitting. The objective of this study is to determine the degree of spatial variability of EC (Electric Conductivity), $\mathrm{pH}$, Organic carbon (OC), Nitrogen $(\mathrm{N})$, Potassium (K), Phosphorus (P) Sulphur (S) and Zinc (Zn) with classical and geo statistical analysis for Katni districts of Madhya Pradesh.

\section{MATERIALS AND METHODS}

\subsection{Site Description}

Katni district is situated in the east central portion of Madhya Pradesh, India. Physiographically, the study area falls between $23^{\circ} 17^{\prime} 44.93^{\prime \prime} \mathrm{N}$ to $247^{\prime} 44.06 " \mathrm{~N}$ and $798^{\circ} 53.88 \mathrm{E}$ to $806^{\prime} 45.03$ "E and covers $4,949 \mathrm{~km} 2$ areas, which comes under Kymore Plateau and Satpura Hills Agro Climatic Zone (Zone-VII). The valley in the middle part occupied by Mahakoshal group of rocks and alluvial plains. The variety of soil ranging from clay to silty clay and from loamy to clay loam is distributed all over the district. The climate is subtropical, highest temperature is 
reached till $46{ }^{\circ} \mathrm{C}$ in May and lowest is $5^{\circ}$ in January. The slope of the district is facing gradually from south to north. It has an average elevation of 390 meters.

\subsection{Soil Sampling and Analysis}

This study was conducted in Katni district of Madhya Pradesh. The soils of the study area are light to medium and some parts of the region are heavy in texture. About 505 surface soil samples $(0-15 \mathrm{~cm})$ were collected by using GPS from 6 blocks of Katni district, viz; Murwara, Vijay raghavgarh, Barhi, Badwara, Dhimarkhera and Rithi. The available N, P, K, Zn, S along with $\mathrm{pH}$, $\mathrm{EC}$, and organic carbon (OC) were analyzed in a laboratory. The soil samples were air-dried and ground to pass a $2 \mathrm{~mm}$ sieve for the analysis of soil $\mathrm{pH}$, and macro nutrients (N, $\mathrm{P}$ and $\mathrm{K}$ ) and micro-nutrients $(\mathrm{Zn}$, and $\mathrm{S})$. Soil $\mathrm{pH}$ was determined with a $\mathrm{pH}$ electrode at a soil to water. Walkley and Black methodology for Organic Carbon [18], alkaline permanganate methodology for nitrogen content [19] and Ammonia Acetate methodology for Potassium content extraction [20] were used.

\subsection{Statistical and Geostatistical Analysis}

The main statistical parameters, including mean, median, standard deviation, variance, coefficient of variance, and maximum and minimum values, which are generally accepted as indicators of the central tendency and of the data spread, were analyzed. The Pearson correlation coefficients were estimated for all possible paired combinations of the response variables to generate a correlation coefficient matrix. These statistical parameters were calculated in Microsoft Excel.

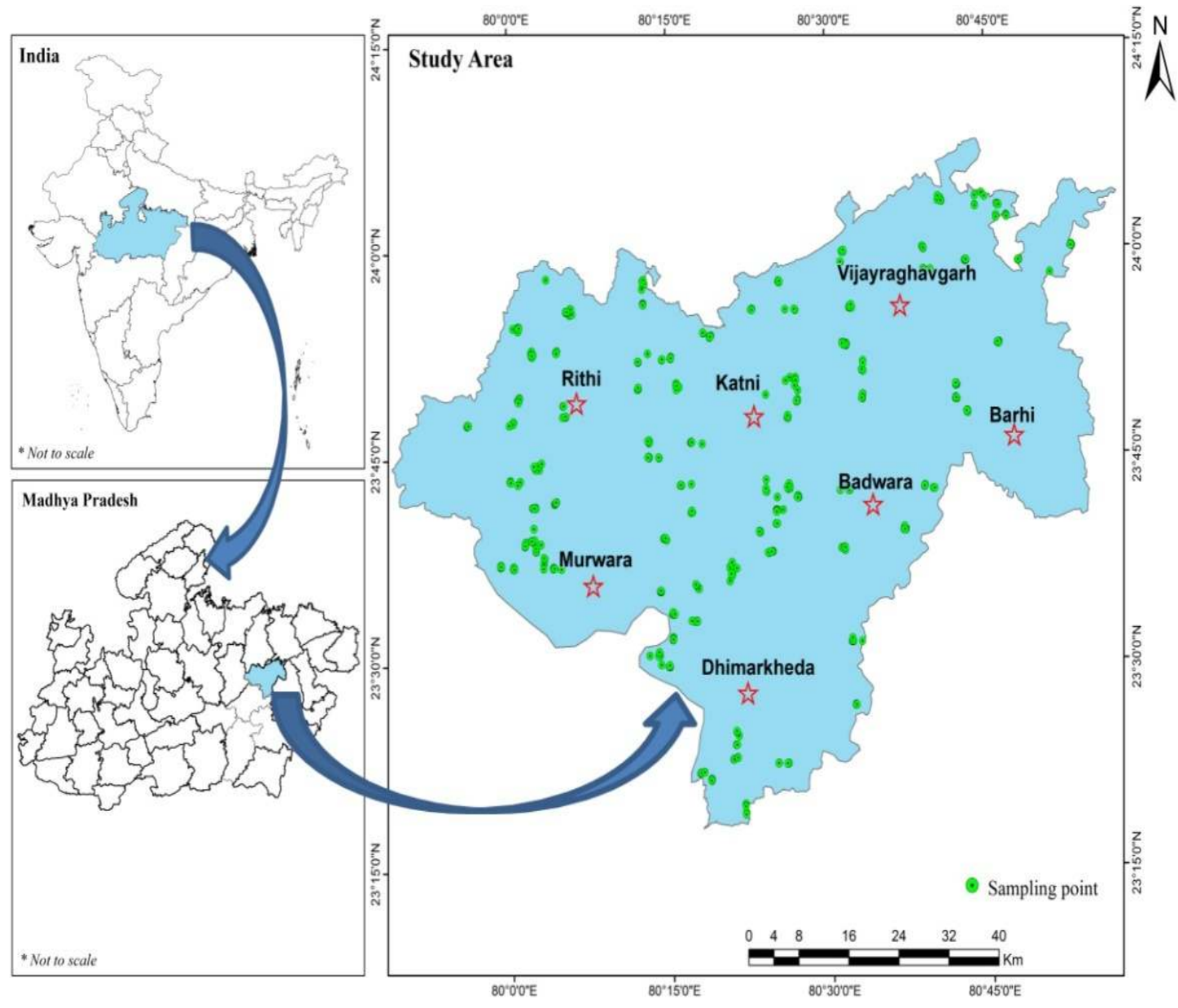

Fig. 1. Location map of the study area 
The semi-variogram is half the expected squared difference between paired data values $Z[x]$ and $Z[x+h]$ to the lag distance $\mathrm{h}$, by which locations are separated [21].

$$
y(h)=\frac{1}{2} E[z(x)-z(x+h)]^{2}
$$

The usual computing equation for the variogram is:

$$
\gamma(h)=\frac{1}{2 N(h)} \sum_{i=1}^{N(h)}\left[z\left(x_{i}\right)-z\left(x_{i}+h\right)\right]^{2}
$$

Where $Z\left(x_{i}\right)$ is the value of the variable $Z$ at location of $x_{i}, \mathrm{~h}$ is the lag distance and $N[h]$ is the number of pairs of sample points separated by $h$. For irregular sampling, it is rare for the distance between the sample pairs to be exactly equal to $h$. Therefore, the lag distance $\mathrm{h}$ is often represented by a distance band.

Semi-variogram model is only an approximation of spatial variability of the measured conditions, appraised by means of cross-validation procedure, cross-validation was used to obtain study by better resolving the spatial structure predicted and measured values. In this study, Omni directional semi-variogram was computed for each soil property because no significant directional trend was observed. Best-fit model with minimum root mean square error (RMSE) and root mean square standardized (prediction) errors (RMSSE) close to 1 were selected for each soil property. The expression of RMSE is given below.

$$
R M S E=\sqrt{\frac{1}{n}} \sum_{j=1}^{n}\left(\gamma_{j}-\hat{\gamma}_{j}\right)^{2}
$$

Where $\widehat{y}_{j}$ is the predicted value, $\gamma_{j}$ the observed value and $\mathrm{n}$ the number of values in the dataset Finally, the cross-validation method was applied to validate the parameters of the model [22]. Eight commonly used semivariogram models were fitted for each soil property. These are the Circular, spherical, Tetraspherical, Pentas pherical exponential, Gaussian, Rational Quadrate and hole-effect model. In GIS domain, Arc GIS Geo statistical analyst extension was used to carry out exploratory variogram analysis, and then this exploratory approach was extended to spatial interpolation by way of kriging. Geostatistical analysis consisting of semi-variogram calculation, kriging, cross-validation, and mapping was performed using the geo statistical analyst extension of Arc GIS 9.3.

\subsection{Validation of Soil Maps}

Accuracy of the soil maps was evaluated through cross-validation approach [23]. Among three evaluation indices used in this study, i.e. mean absolute error (MAE), mean squared error (MSE) and goodness of prediction (G). Where in MAE and MSE measure the accuracy of prediction, whereas (G) measures the effectiveness of prediction. MAE is a measure of the sum of the residuals (e.g. predicted minus observed) [24].

$$
M A E=\frac{1}{n} \sum_{i=1}^{n} \mid z^{*}\left(x_{i}\right)-z\left(x_{i}\right)
$$

Where, (xi) is the predicted value at location $\mathrm{i}$. Small MAE values indicate few errors. The MAE measure, however, does not reveal the magnitude of error that might occur at any point and hence MSE will be calculated,

$$
M S E=\frac{1}{n} \sum_{i=1}^{n}\left[z_{1}\left(x_{i}\right)-z_{2}\left(x_{i}\right)\right]
$$

Squaring the difference at any point gives an indication of the magnitude, e.g. small MSE values indicate more accurate estimation, pointby-point. The $G$ measure gives an indication of how effective a prediction might be relative to that which could have been derived from using the sample mean alone [25].

$$
\mathrm{G}=\left[1-\frac{\sum_{i=1}^{N}\left[z\left(x_{i}\right)-z^{\wedge}\left(x_{i}\right)\right]^{2}}{\sum_{i=1}^{N}\left[z\left(x_{i}\right)-z^{-}\right]^{2}}\right] \times 100
$$

Where $z$ is the sample mean. If $G 100$, it indicates perfect prediction, whereas negative values indicate that the predictions are less reliable than using sample mean as the predictors. The comparison of performance between interpolations was achieved by using mean absolute error (MAE).

\section{RESULTS}

\subsection{Descriptive Statistics}

Descriptive statistics for the analyzed 505 soil samples for different soil parameters are summarized in Table 1. The minimum, maximum, mean, median, standard deviation 
(SD), skewness, kurtosis and coefficient of variation (CV) describe distribution of soil property. The coefficient of variation is the ratio of standard deviation to mean is a useful measure of overall variability. There was difference in CV of soil properties. The greatest variation was observed in $\mathrm{Zn}(140 \%)$ where as the smallest variation of soil $\mathrm{pH}(14.16 \%)$. The normality of data distribution are analyzed by plotting the histogram. If a variable has positive ske wness, the confidence limits on the variogram are wider than they would otherwise be and consequently, the variances are less reliable. A logarithmic transformation is considered where the coefficient of ske wness is greater than one [21]. Therefore, a logarithmic transformation was performed for EC, P S and available Zinc $(Z n)$ parameters because their skewness was greater than 1 .

\subsection{Semi-variogram of Soil Properties}

RMSE and RMSSE are shown in Table 2 for different theoretical semivariogram models to fit the experimental semivariogram values for each soil property. Among different theoretical models tested, the Exponential model was found as the best fit in most cases. In case of EC, spatial variation was the best described by the spherical model.

Table 1. Descriptive statistics of soil parameters $(0-15 \mathrm{~cm}$ depth) of 505 soil samples

\begin{tabular}{llllllllll}
\hline $\begin{array}{l}\text { Para- } \\
\text { meters }\end{array}$ & Mini. & Maxi. & Median & Mean & Std. & \multicolumn{3}{c}{ Skewness Skewness } & Kurtosis CV\% \\
(Log Tran.) & & \\
\hline pH & 4.00 & 8.00 & 6.60 & 6.48 & 0.92 & -0.42 & - & 2.49 & 14.16 \\
EC & 0.01 & 0.97 & 0.12 & 0.14 & 0.10 & 3.96 & 0.1653 & 24.97 & 73.51 \\
OC & 0.18 & 0.99 & 0.65 & 0.65 & 0.17 & -0.27 & - & 2.70 & 25.68 \\
N & 102.19 & 454.03 & 310.42 & 309.44 & 81.37 & -0.36 & - & 2.62 & 26.29 \\
P & 2.38 & 42.37 & 10.30 & 14.08 & 11.36 & 1.01 & -0.0061 & 2.87 & 80.74 \\
K & 101.92 & 795.20 & 393.68 & 395.84 & 165.38 & 0.22 & - & 2.52 & 41.78 \\
S & 3.45 & 49.68 & 13.80 & 15.35 & 7.76 & 1.01 & -0.4645 & 4.60 & 50.58 \\
Zn & 0.01 & 10.20 & 0.51 & 0.81 & 1.14 & 4.27 & 0.1529 & 25.33 & 140.19 \\
\hline
\end{tabular}

Table 2. Parameters for different theoretical semi variogram models

\begin{tabular}{lllllllll}
\hline \multirow{2}{*}{$\begin{array}{l}\text { Semivariogram } \\
\text { model }\end{array}$} & \multicolumn{9}{c}{ Soil properties } \\
\cline { 2 - 9 } & $\mathbf{p H}$ & $\mathbf{E C}$ & $\mathbf{O C}$ & $\mathbf{N}$ & $\mathbf{P}$ & $\mathbf{K}$ & $\mathbf{S}$ & $\mathbf{Z n}$ \\
\hline Circular & 0.7649 & 0.1047 & 0.1596 & 77.21 & 11.38 & 166.2 & 7.077 & 1.099 \\
Spherical & 0.7616 & $\mathbf{0 . 1 0 4 7}$ & 0.1596 & 77.20 & 11.39 & 165.9 & 7.059 & 1.099 \\
Tetraspherical & 0.7588 & 0.1047 & 0.1595 & 77.18 & 11.36 & 165.9 & 7.056 & 1.099 \\
Pentaspherical & 0.7562 & 0.1048 & 0.1595 & 77.16 & 11.36 & 165.8 & 7.057 & 1.098 \\
Exponential & $\mathbf{0 . 7 3 1 8}$ & 0.1049 & $\mathbf{0 . 1 5 9 0}$ & $\mathbf{7 6 . 9 6}$ & $\mathbf{1 1 . 3 1}$ & $\mathbf{1 6 4 . 4}$ & $\mathbf{6 . 9 2 3}$ & $\mathbf{1 . 0 9 7}$ \\
Gaussian & 0.8083 & 0.1048 & 0.1602 & 77.55 & 11.41 & 168.4 & 7.191 & 1.102 \\
Rational Quadrate & 0.7857 & 0.1049 & 0.1599 & 77.32 & 11.38 & 167.3 & 6.952 & 1.101 \\
Hole Effect & 0.8067 & 0.1048 & 0.1602 & 77.52 & 11.4 & 168.6 & 7.317 & 1.101 \\
\hline
\end{tabular}

Table 3. Semi variogram parameters of Soil Nutrients

\begin{tabular}{lllllll}
\hline $\begin{array}{l}\text { Soil } \\
\text { nutrient }\end{array}$ & $\begin{array}{l}\text { Fitted Semi } \\
\text { variogram Model }\end{array}$ & $\begin{array}{l}\text { Range } \\
(\mathbf{k m})\end{array}$ & $\begin{array}{l}\text { Nugget } \\
(\mathbf{C 0})\end{array}$ & Partial Sill (C) & Sill & $\begin{array}{l}\text { Nugget/ } \\
\text { Sill }(\%)\end{array}$ \\
\hline pH & Exponential & 95.80 & 0.4954 & 0.5405 & 1.04 & 47.82 \\
EC & Spherical & 92.57 & 0.0106 & 0.00569 & 0.02 & 65.21 \\
OC & Exponential & 95.80 & 0.0234 & 0.00669 & 0.03 & 77.77 \\
N & Exponential & 95.80 & 5483.6 & 1672 & 7155.60 & 76.63 \\
P & Exponential & 24.83 & 123.14 & 6.5539 & 129.69 & 94.95 \\
K & Exponential & 95.80 & 24324 & 8873 & 33197 & 73.25 \\
S & Exponential & 17.70 & 0.2136 & 0.07385 & 0.29 & 74.31 \\
Zn & Exponential & 41.97 & 0.7803 & 0.11996 & 0.90 & 86.68 \\
\hline
\end{tabular}


Semi-variogram parameters (range, nugget and sill) and nugget sill ratio for each soil property with the best-fitted model are shown in Table 3. The range expressed as distance could be interpreted as the diameter of the zone of influence that represented the average maximum distance over which a soil property of two samples was related. At distances less than the range, measured properties of two samples became similar with decreasing distance between the two points. Thus, the range provided an estimate of areas of similarity. The ratio of nugget to sill considered to have a strong spatial dependence if the ratio is less than $25 \%$ and has a moderate spatial dependence if the ratio is between 25 to $75 \%$. Otherwise the variable has a weak spatial dependence [26]. The nugget sill ratio of $\mathrm{pH}, \mathrm{EC}, \mathrm{K}$ and $\mathrm{S}$ shows moderate spatial dependency where as OC, N, P and $\mathrm{Zn}$ shows weak spatial dependency.

\subsection{Ordinary Kriging and Cross-validation}

Spatial maps prepared through ordinary kriging (Exponential and Spherical) using the semi variogram parameters were cross-validated by leaving $10 \%$ sample out and predicting for that sample location based on rest of the samples. Result from cross-validation of spatial maps of soil properties are given in Table 4. This also shows that semi variogram parameters obtained from fitting of experimental semi variogram values were fairly reasonable to describe the spatial variations. Spatial maps of soil properties prepared through ordinary kriging are presented in Figs. 2 to 9. pH, EC, S, Zn and available potassium had almost a similar spatial variability, eq. all soil nutrients decreased from north-east to south west where as $\mathrm{N}$ and $\mathrm{OC}$ shows similar spatial variability.

The critical limit of soil nutrient defined by IISS Bhopal, interpolated maps of the study area show a clear deficiency of soil micro-nutrients. Sulphur is deficient in $94 \%$, Zinc in $20 \%$ of the area where as in case of $\mathrm{pH}$ above $50 \%$ of the soil is acidic in nature.

For all soil parameters, it was observed that the highest Mean Absolute Error (MAE) and Mean Square Error (MSE) was found for $K$, followed by $\mathrm{N}, \mathrm{P}, \mathrm{S}, \mathrm{Zn}, \mathrm{OC}, \mathrm{EC}$ and $\mathrm{pH}$. The goodness of fit (G) values was positive for all soil nutrients except EC and $P$. The highest $G$ value was observed for $\mathrm{pH}$ followed by $\mathrm{K}, \mathrm{S}, \mathrm{OC}, \mathrm{N}$ and $\mathrm{Zn}$. For all the soil nutrients $G$ value was greater than zero,(except EC and $P$ ) which indicates that spatial prediction is better than assuming mean of observed value for any un sampled location. Therefore it is a suitable alternative method for accurate estimation of chemical properties of soil in un-sampled positions as compared to direct measurement which has time and costs concern [27].

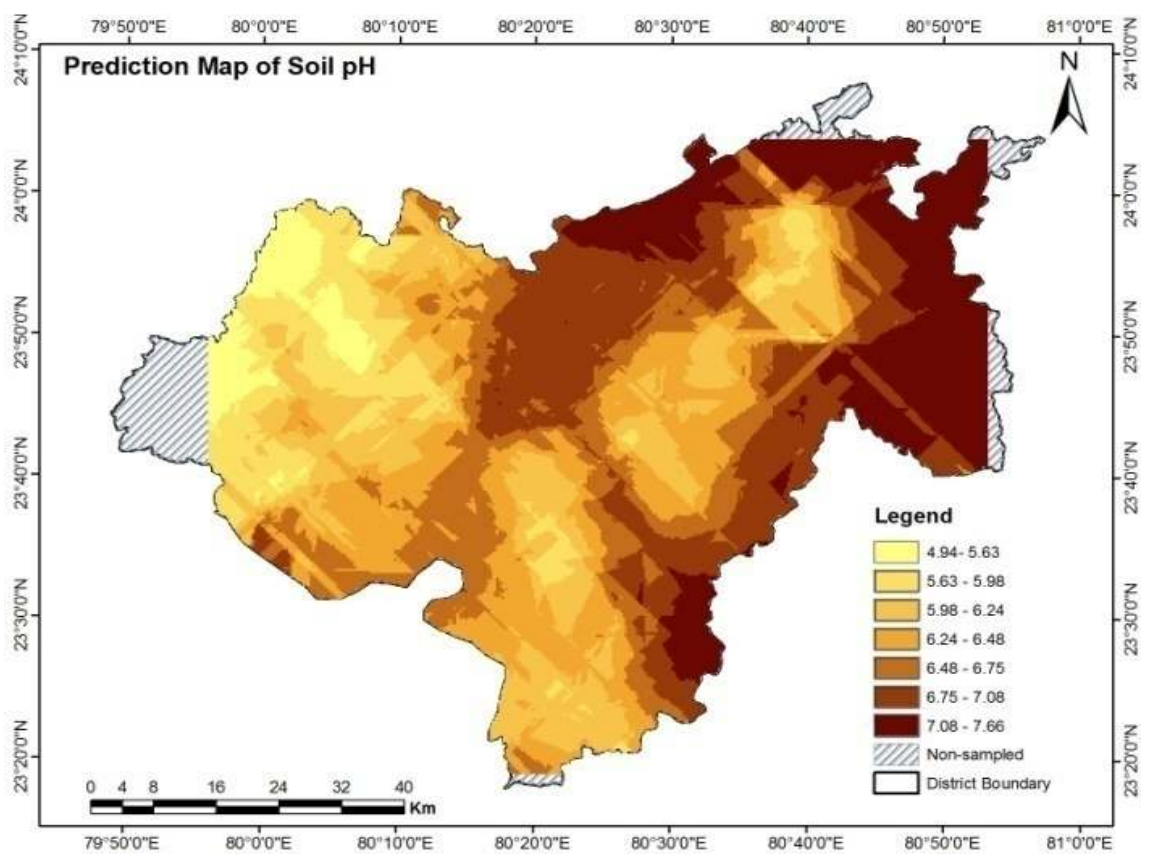

Fig. 2. Soil pH 
Dey et al.; IJPSS, 17(3): 1-13, 2017; Article no.IJPSS.34219

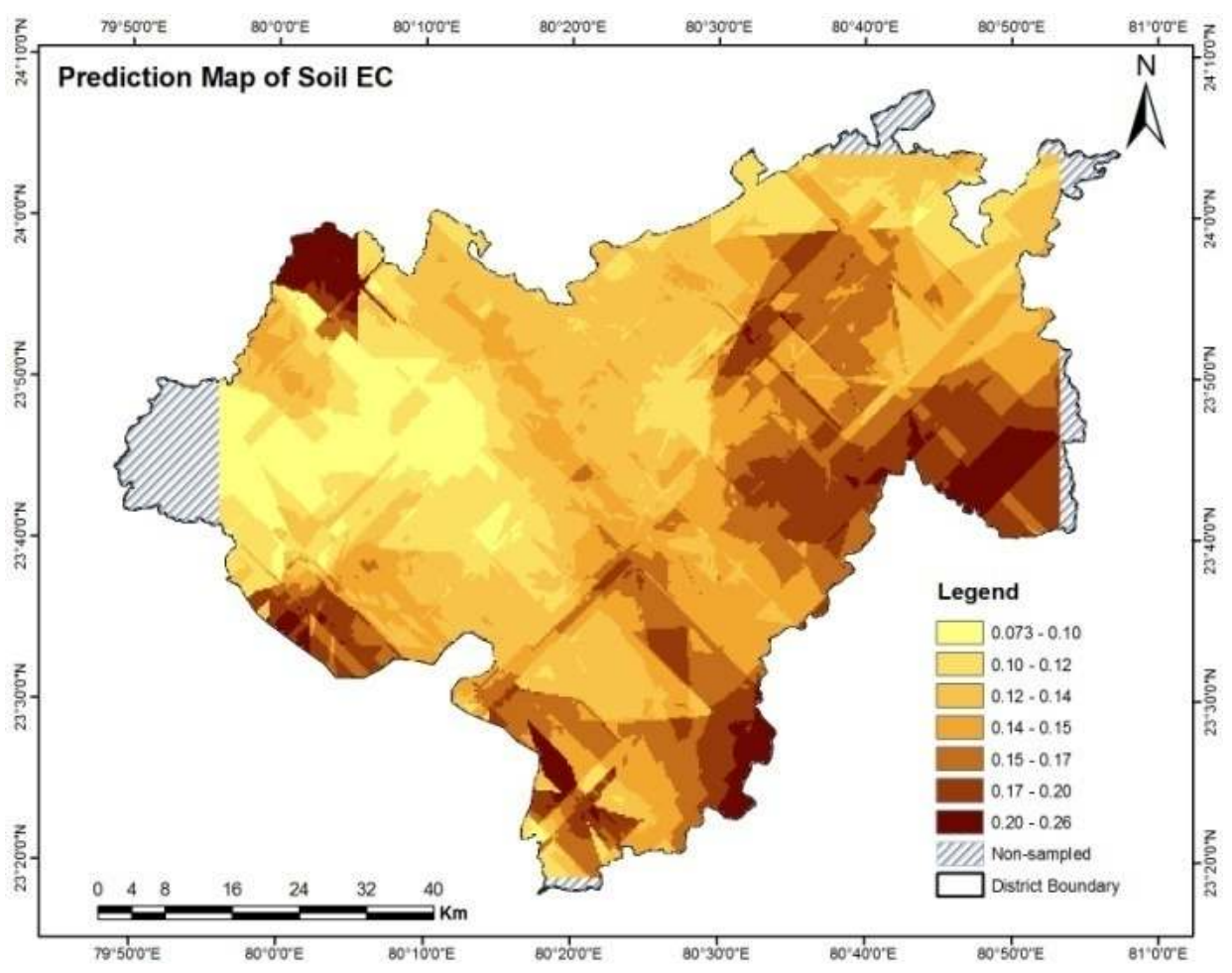

Fig. 3. Soil EC

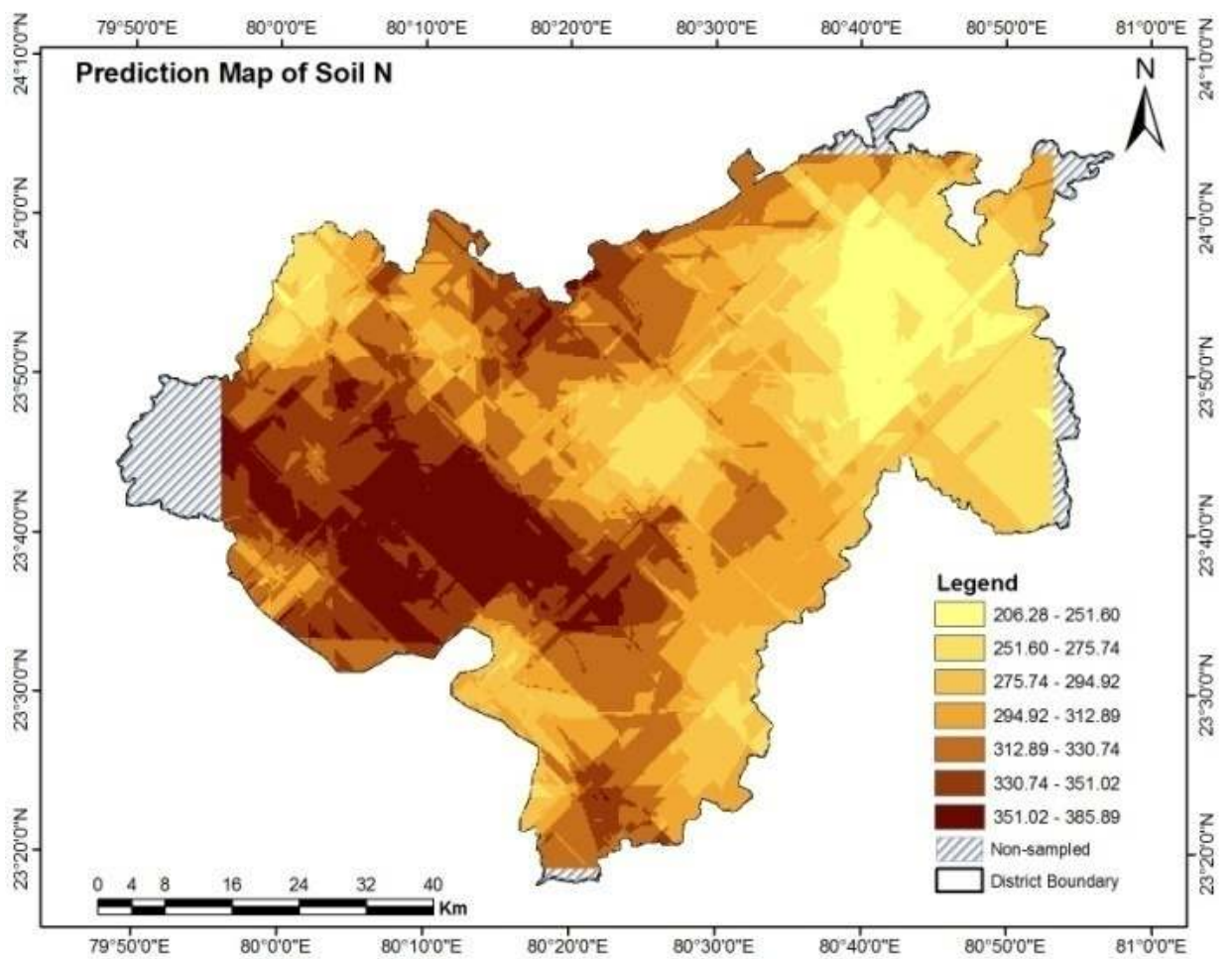

Fig. 4. Soil Nitrogen (N) $\left(\mathrm{kg} \mathrm{ha}^{-1}\right)$ 
Dey et al.; IJPSS, 17(3): 1-13, 2017; Article no.IJPSS.34219

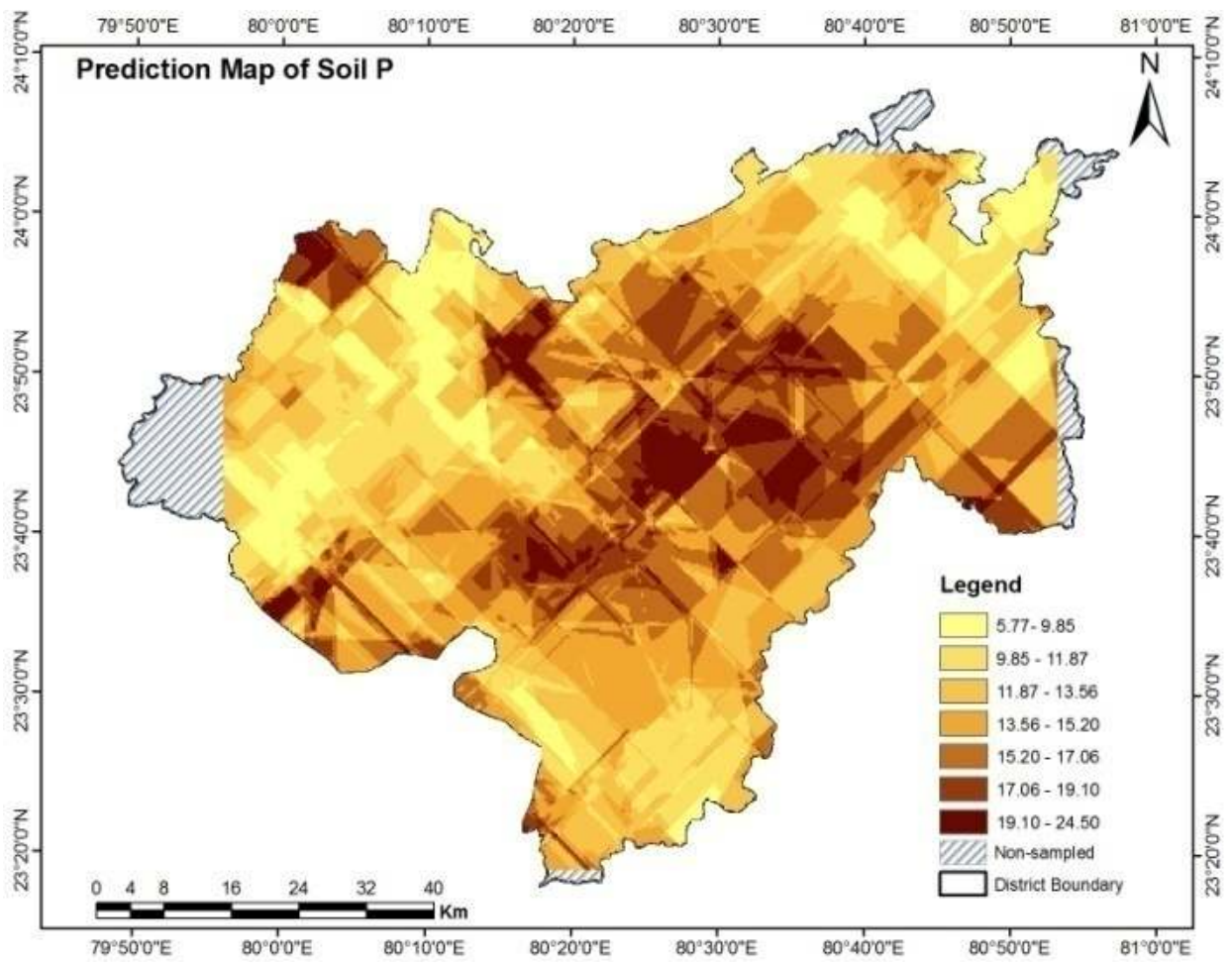

Fig. 5. Soil phosphorus (P) $\left(\mathrm{kg} \mathrm{ha}^{-1}\right)$

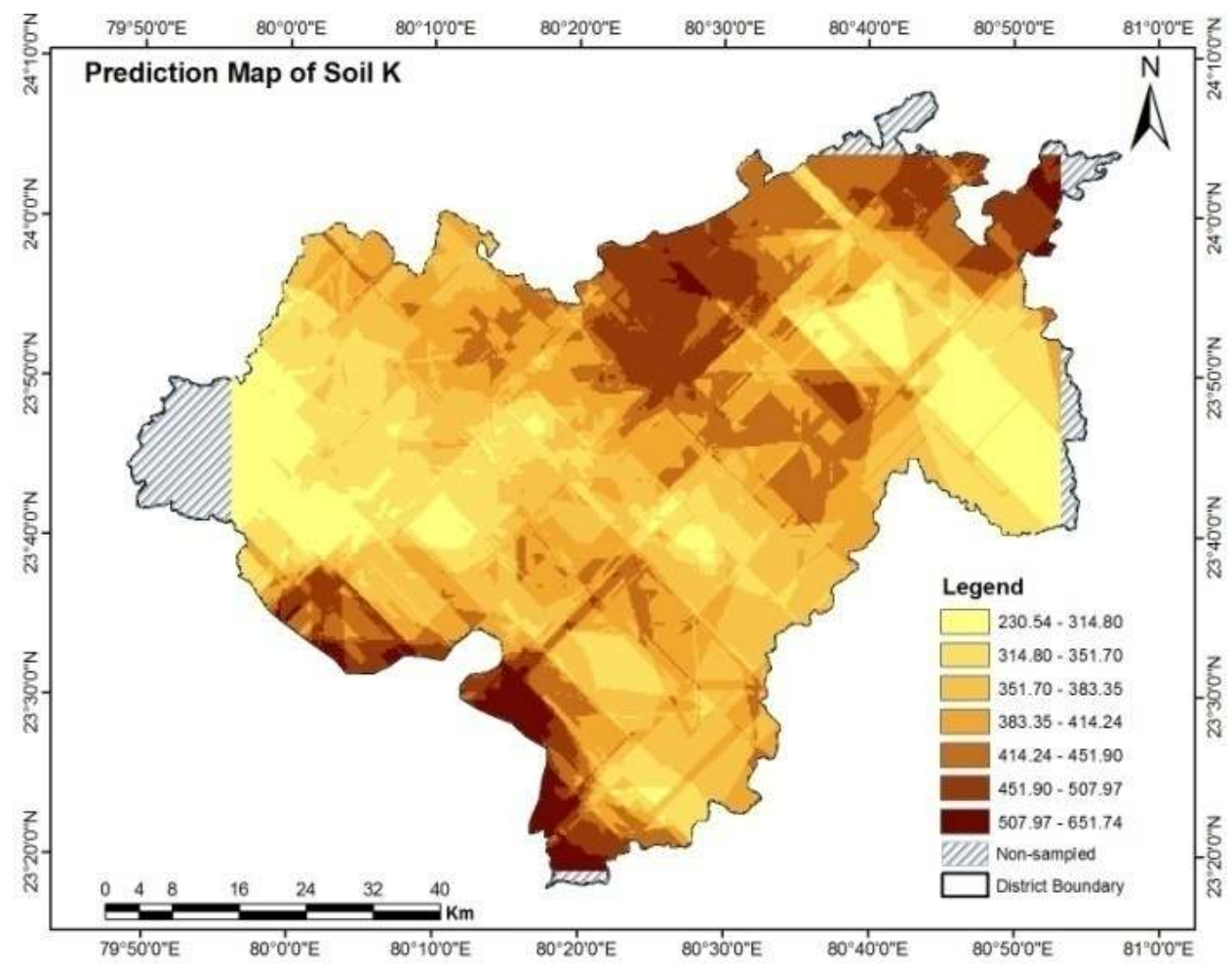

Fig. 6. Soil potassium (K) (kg ha $\left.{ }^{-1}\right)$ 
Dey et al.; IJPSS, 17(3): 1-13, 2017; Article no.IJPSS.34219

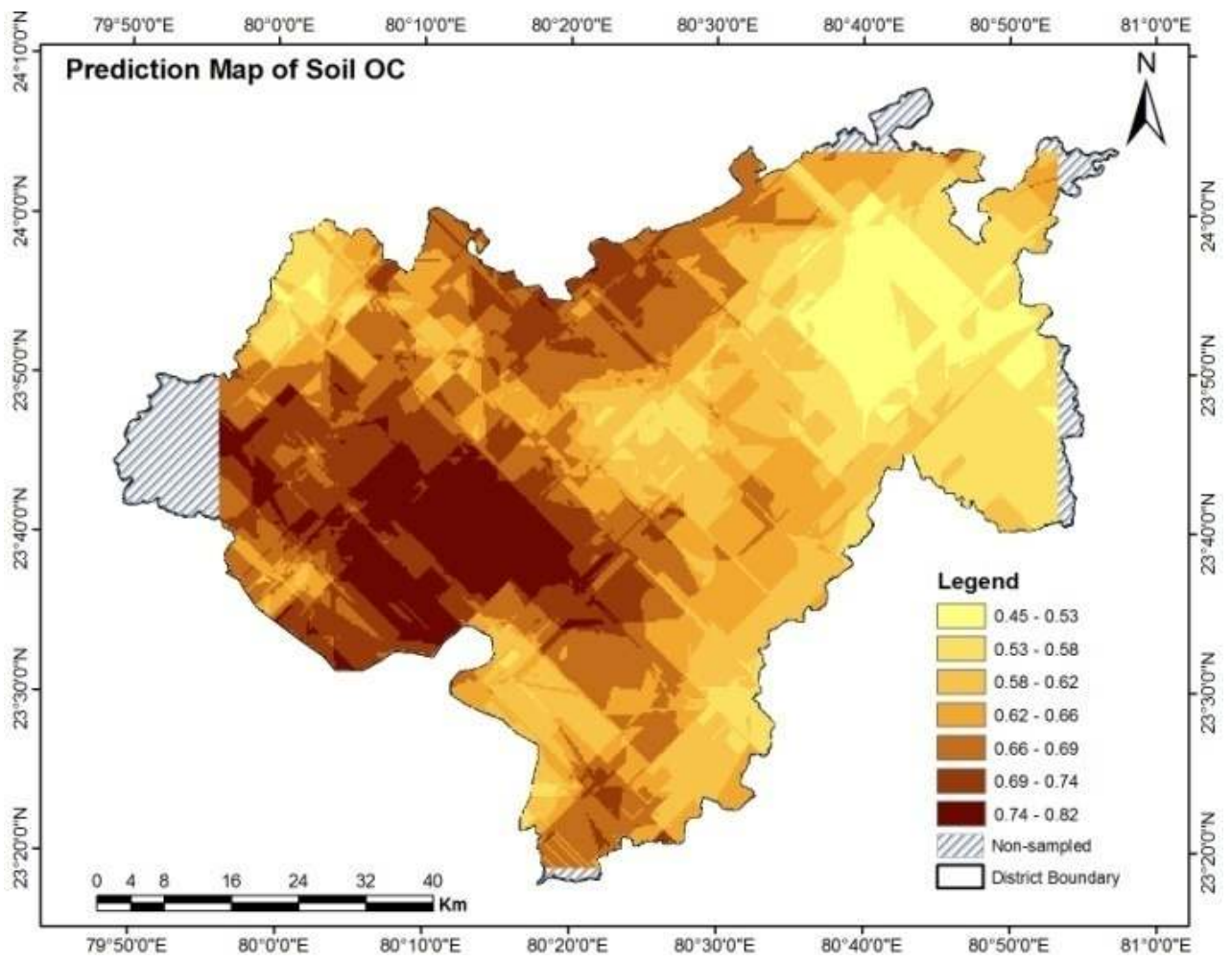

Fig. 7. Soil organic carbon (OC) (\%)

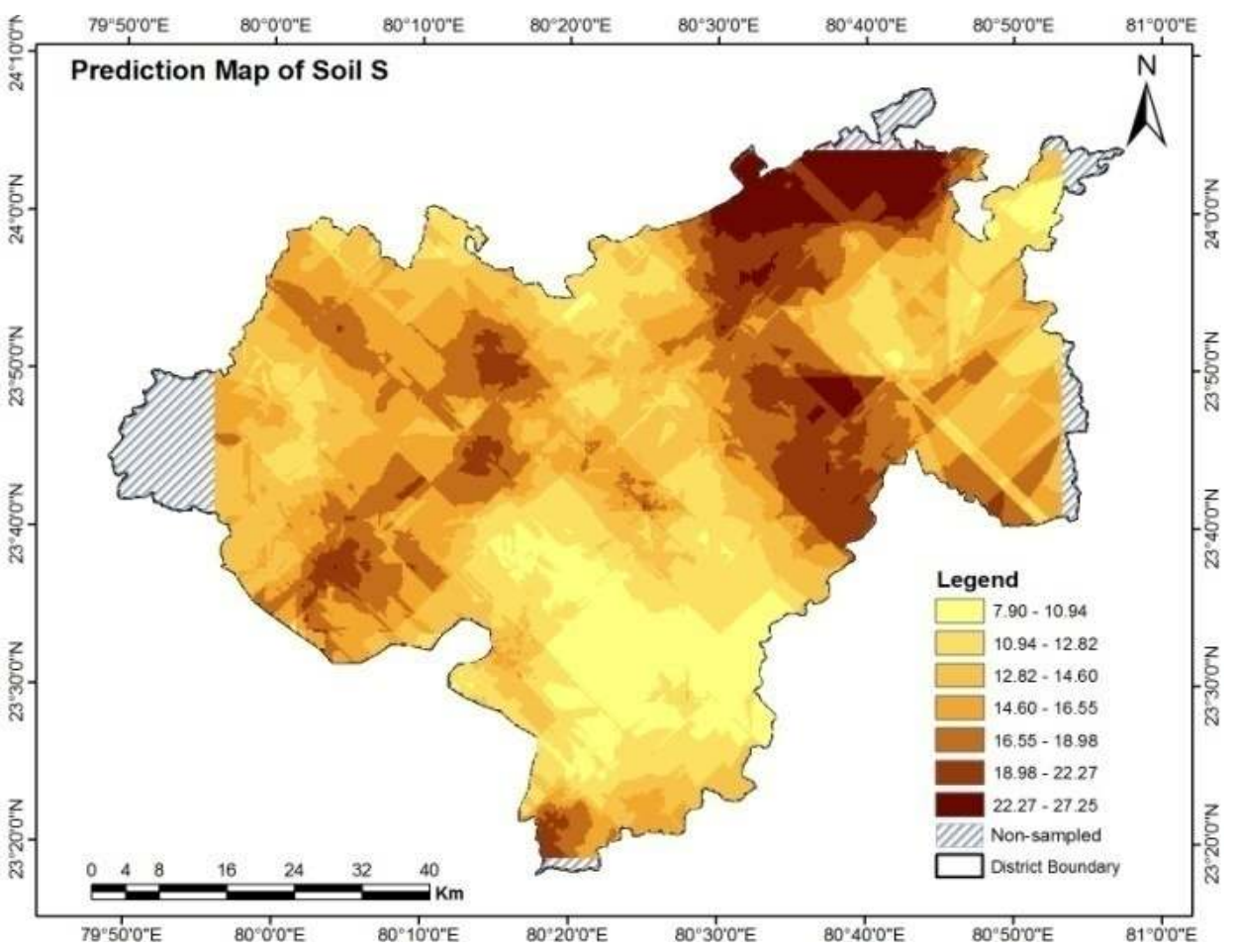

Fig. 8. Soil Sulphur (S) (kg ha-1) 


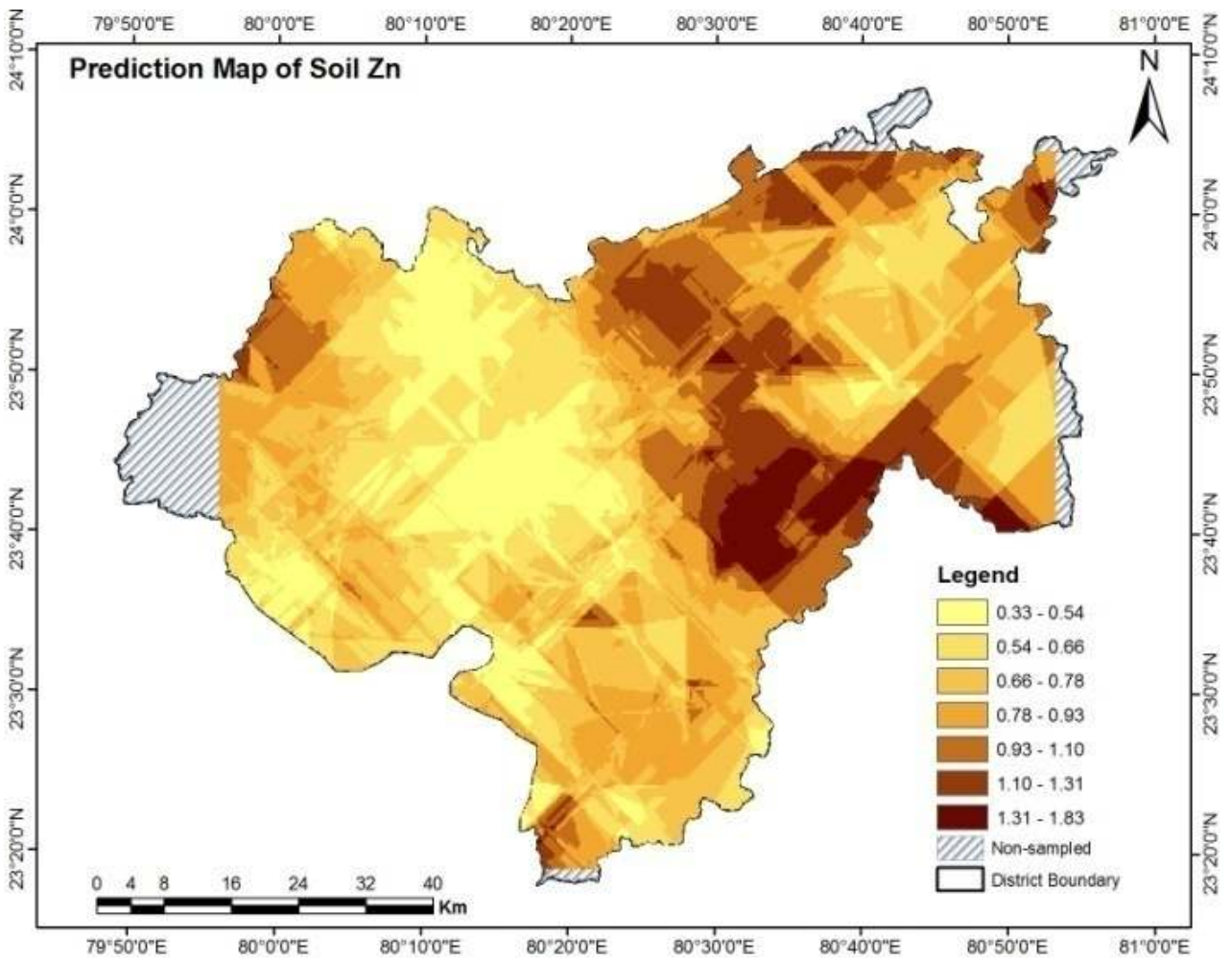

Fig. 9. Soil zinc (Zn)

Table 4. Evaluation of ordinary kriging map of soil nutrients through cross-validation

\begin{tabular}{llll}
\hline Soil nutrient & $\begin{array}{l}\text { Mean absolute error } \\
\text { (MAE) }\end{array}$ & $\begin{array}{l}\text { Mean square error } \\
\text { (MSE) }\end{array}$ & $\begin{array}{l}\text { Goodness of } \\
\text { prediction (G) }\end{array}$ \\
\hline pH & 0.058 & 0.5355 & 35.98 \\
$\mathrm{EC}$ & 0.059 & 0.0109 & -7.85 \\
$\mathrm{OC}$ & 0.127 & 0.025293 & 15.13 \\
$\mathrm{~N}$ & 62.031 & 5923.003 & 14.78 \\
$\mathrm{P}$ & 8.992 & 127.944 & -1.11 \\
$\mathrm{~K}$ & 131.646 & 27031.87 & 22.044 \\
$\mathrm{~S}$ & 5.059 & 47.930 & 21.21 \\
$\mathrm{Zn}$ & 0.574 & 1.20292 & 11.48 \\
\hline
\end{tabular}

Table 5. Pearson's correlation coefficients between soil properties

\begin{tabular}{|c|c|c|c|c|c|c|c|c|}
\hline & pH & EC & OC & $\mathbf{N}$ & $\mathbf{P}$ & K & $S$ & $Z n$ \\
\hline $\mathrm{pH}$ & 1.000 & & & & & & & \\
\hline EC & 0.151 & 1.000 & & & & & & \\
\hline OC & -0.015 & 0.004 & 1.000 & & & & & \\
\hline $\mathrm{N}$ & -0.048 & 0.005 & $0.955^{\star \star}$ & 1.000 & & & & \\
\hline $\mathrm{P}$ & -0.019 & 0.076 & 0.075 & 0.069 & 1.000 & & & \\
\hline K & $0.311^{\star \star}$ & 0.111 & -0.057 & -0.080 & $0.187^{\star}$ & 1.000 & & \\
\hline S & 0.034 & 0.034 & 0.074 & 0.077 & 0.017 & 0.065 & 1.000 & \\
\hline $\mathrm{Zn}$ & -0.073 & -0.034 & 0.027 & 0.040 & 0.032 & 0.005 & 0.051 & 1.000 \\
\hline
\end{tabular}




\subsection{Relation between Soil Nutrients}

The Pearson's correlation coefficients Correlation studies shows that positive correlation between organic carbon with Nitrogen $(r=0.955)$ and $K$ with $\mathrm{pH} \quad(\mathrm{r}=0.311$.$) Where as other soil$ parameter shows very low or no correlation between each other.

\section{DISCUSSION}

There are number of spatial interpolation methods which are commonly used for spatial interpolation of soil characteristics/nutrients. The most frequently used is ordinary kriging $[26,27,28]$. Measures for assessing the performance of the spatial interpolation methods are based on prediction errors such as the RMSE. Compared spatial interpolation methods revealed that for spatial distribution of soil nutrients, methods that showed the best performance are exponential and Spherical models. In general, geo statistical methods (kriging) were more frequently recommended than non-geo statistical methods (e.g., Basic Statistics). In our study, the interpolation method that produced the smallest RMSE was exponential and spherical. This finding is consistent with [26] who found that exponential model were best fitted for $\mathrm{pH}, \mathrm{OC}, \mathrm{N}$ and $\mathrm{K}$ for spatial interpolation on similar type of soil texture (Brahmaputra plain, North eastern India). In a similar study of interpolation methods, [29] compared four prediction methods; they found that no one methods were suitable but different methods should be used for different nutrient. He found that ordinary kriging best suited for organic carbon where as IDW and spline for electric conductivity.

With respect to soil specific properties, Phosphorus (P) and Electric Conductivity (EC) were the only soil nutrients for which Goodness of prediction $\mathrm{G}$ had a negative value. It shows that the prediction would have been more reliable if the sample means (Basic statistics) had been used instead. Moreover, in the exploratory analysis these nutrients did not reveal any kind of tendency and it was not easy to detect any spatial arrangement. Therefore, it should have been excluded in advance from further analysis. The rest of the soil properties had positive G values, indicating that the interpolation model used for nutrient mapping was suitable. The source of errors and uncertainties of the prediction maps can be minimized by selecting different kriging parameters instead of default values. It might leads to different or better results in this study, and also it would be highly useful to change the sampling strategy and compare these results with the differently sampled points. It is also suggested that for mapping of spatial distribution, other parameters such as slope gradient, soil type and land use pattern should also be considered. It can greatly influence the concentration of the soil nutrients and their spatial distribution significantly.

The other set of methods i.e. Deterministic could have been used along with the non-deterministic methods but the preference was given to find the real processes which gave rise the spatial variations measured in this study. One of the best way is to find out is to prepare semivariogram and complement it with other statistical indicators such as correlation. This approach has worked quite well here as we could find a similar semi-variogram for $\mathrm{N}$ and organic carbon with high correlation coefficient. It indicates that both the macro-nutrient complement each other in the study area. It, however, cannot be denied that deter ministic methods has their own usefulness and in many cases they prove more useful than nondeterministic.

The interpolated map shows clear deficiency of soil micro-nutrients across the district. Sulphur is deficient in $94 \%$, Zinc in $20 \%$ of the area where as above $50 \%$ of the soil is acidic in nature $(\mathrm{pH}<$ 6.5). In the study area, more than $85 \%$ of the irrigated area has a fine soil texture. The important factors which affect the soil fertility is cropping practices resulted emergence of multiple nutrient deficiencies in the area especially if proper dose of additional fertilizer not provided in the required ratios. The deficiency of essential micro-nutrients in such a big area is, indeed, alarming. Appropriate measures should be taken to maximize the crop yield in the district. Since the water scarcity is not a problem in the area, crop yield can, suitably, be increased too much higher levels to the present levels. Furthermore, continuous monitoring of soil quality and nutrient values will further help in ensuring soil fertility. Continuous monitoring will, in addition, help to sustain the land productivity once it is achieved by the right crop practices and fertilizers. In the future researches, more micro-nutrients should be included along with the cropping pattern details. These analyses would further sharpen the results and narrow down the nutrient-deficient areas. In such an Endeavour, Remote Sensing and GIS will play a major role by providing land use/land cover details. 


\section{CONCLUSION}

The descriptive statistics of soil nutrients shows that in the raw data sets of EC, $P, S$ and $Z n$ are strongly positively skewed (greater than 1) and the application of logarithmic transformation was used for normalization, which affects the data. Among different models tested for analyzing the spatial variability of soil nutrients the exponential model fits well of $\mathrm{pH}, \mathrm{OC}$, available $\mathrm{N}, \mathrm{P}, \mathrm{K}, \mathrm{S}$ and $\mathrm{Zn}$ where as in case of Electric conductivity (Ec) best fitted model was spherical. Soil properties showed large variability with greatest variation observed in $\mathrm{Zn}(140 \%)$ whereas the smallest variation was in $\mathrm{pH}(14.16 \%)$. In case of $E C$ and $P$ the goodness of prediction $(G)$ had a negative value while $\mathrm{N}, \mathrm{P}, \mathrm{K}, \mathrm{pH}, \mathrm{Zn}$ and $\mathrm{S}$ shows positive value. The kriged interpolated map of $\mathrm{S}, \mathrm{Zn}$ and $\mathrm{pH}$ values in north-east part of the study area was alkaline and in the south-west portion of area has acidic in nature. Nitrogen and organic carbon had strong correlation coefficient $(r=0.955)$ and as expected both the parameters were best modeled by exponential model. This further indicates that distributions of both the nutrients are governed by same process. The soil properties of both nutrients increased in southern part of the study area and decrease towards eastern part of the study area.

Since we have tested the random sampled points, it would be highly useful to change the sampling strategy and compare these results with the differently sampled points.

\section{COMPETING INTERESTS}

Authors have declared that no competing interests exist.

\section{REFERENCES}

1. Thilagam VK, Sivasamy R. Role of remote sensing and gis in land resource inventorya review. Agri. Reviews. 2013;34(3):223229.

2. Goovaerts P. Characterizing the Geo statistical tools spatial variability for of microbiological and physico-chemical soil properties. Biology and Fertility Soils. 1998;27:315-334.

3. Carter MR, Gregorich EG, Anderson DW, Doran JW, Janzen $\mathrm{HH}$, Pierce FJ. Concepts of soil quality and their significance. In: Gregorich, EG, Carter MR. (Eds.). Soil quality for crop production and ecosystem health. Elsevier, Amsterdam. 1997;1-19.

4. Haynes RJ, Dominy CS, Graham $\mathrm{MH}$. Effect of agricultural land use on soil organic matter status and the composition of earthworm communities in KwaZuluNatal, South Africa. Agriculture Ecosystem and Environment .2003;95:453-464.

5. Franzluebbers AJ, Hons FM. Soil-profile distribution of primary and secondary plant available nutrients under conventional and no tillage. Soil and Tillage Research. 1996;39:229-239.

6. Atherton BC, Morgan MT, Shearer SA, Stombaugh TS, Ward AD. Site-specific farming: A perspective on in fortnation need, benefits and limitations. Journal of Soil Water Conservation. 1999;54:455461.

7. Malhi SS, Grant CA, Johnston AM, Gill KS. Nitrogen fertilization management for no till cereal production in the Canadian Great Plains: A review. Soil and Tillage Research. 2001;60:101-122.

8. Santra P, Chopra UK, Debashis Chakraborty. Spatial variability of soil properties and its application in predicting surface map of hydraulic parameters in an agricultural farm. Current Science. 2008;95:937-945.

9. Burgess TM, Webster R. Optimal interpolation and is arrhythmic mapping of soil properties: N. Block Kriging. Journal of Soil Science. 1980;31:333-341.

10. Webster R. The development of pedometrics. Geoderma.1994;62:1-15.

11. Zhang CS, Selinus O, Wong P. Spatial structures of cobalt lead and zinc contents in tills in southeastern Sweden. GFF Transactions of tire Geological Society in Stockholm. 2000;122:213-217.

12. Isaake $\mathrm{EH}$, Srivastava RM. An introduction to applied geo statistics. Academic Press, London;1989.

13. Krige DG. A statistical approach to some basic mine valuation problems on the Witwatersrand. Mining Society South Africa.1951;52:119-139.

14. Kerry R, Oliver MA. Average variogram to guide soil sampling. International Journal of Applied Earth Observation and Geoinformation.2004;5:393-400.

15. Cressie NA. Statistics for spatial data. John Wiley and Sons, Ontario, Canada; 1993.

16. Salder EJ, Busscher WJ, Baur PJ, Karlen DL. Spatial scale requirements for 
precision farming: A case study in the southeastern USA. Agronomy Journal. 1998;90:191-197.

17. Deutsch CV. Geo statistical Reservoir Modeling (1" Eds). Oxford University Press. New York; 2002.

18. Walkley A, Black IA. An examination of the Degtjareff method for determining soil organic matter, and a proposed modification of the chromic soil titration method. Soil Sci. 1934;37:29-38.

19. Subbiah BV, Asija GL. A rapid procedure for estimation of available nitrogen in soils. Current Science, 1956;25:259-260.

20. Hanway JJ, Heidel $H$. Soil analysis methods as used in lowa State College, Soil Testing Laboratory, lowa State College Bull. 1952;57:1-131.

21. Goovaerts P. Geo statistics for natural resources evaluation. Oxford University Press, New York; 1997.

22. Webster R, Oliver MA. Geo statistics for Environmental Scientists. John Wiley \& Sons Ltd, Chichester; 2001.

23. Davis BM. Uses and abuses of crossvalidation in Geo statistics. Mathematical Geology.1987;19:241-248.

24. Voltz M, Webster R. A comparison of kriging. Cubic splines and classification for predicting soil properties from sample information. Journal of Soil Science.1990; 41:473-490.

25. Schloeder CA, Zimmermen NE, Jacobs MJ. Comparison of methods for interpolating soil properties using limited data. Soil Science Society of America Journal. 2001;65:470-479.

26. Reza SK, Baruah Utpal, Sarkar Dipak. Spatial variability of soil properties in Brahmaputra plains of north-eastern India: A geo statistical approach. Journal of the Indian Society of Soil Science. 2012;60(2): 108-115.

27. Tagore GS, Bairagi GD, Sharma R, Verma PK. Spatial variability of soil nutrients using geospatial techniques: A case study in soils of sanwer tehsil of Indore district of Madhya Pradesh. The International archieves of the photo grammetry, remote sensing and spatial information sciences, volume XL-8, 2014 ISPRS technical commission VII Symposium, Hyderabad, India; 2014.

28. Chatterjee S, Santra P, Majumdar K, Ghosh D, Das I, Sanyal SK. Geo statistical approach for management of soil nutrients with special emphasis on different forms of potassium considering their spatial variation in intensive cropping system of west Bengal, India. Environmental Monitoring Assessment. 2015;187:183. DOI: $10.1007 /$ s10661-015-4414-9

29. Robinson TP, Metternicht G. Testing the performance of spatial interpolation techniques for mapping soil properties. Computers and Electronics in Agriculture. 2006;50:97-108.

(0) 2017 Dey et al.; This is an Open Access article distributed under the terms of the Creative Commons Attribution License (http://creativecommons.org/licenses/by/4.0), which permits unrestricted use, distribution, and reproduction in any medium, provided the original work is properly cited.

Peer-review history:

The peer review history for this paper can be accessed here: http://sciencedomain.org/review-history/20006 